\title{
La traducción de los culturemas (Discusión al margen de la traducción de una novela de Guillermo Arriaga)
}

Olivia Narcisa Petrescu Universidad Babes-Bolyai, Cluj-Napoca, Rumania

Resumen

En este artículo nos proponemos revisar, sobre una base léxica y fraseológica, la traducción publicada al rumano de la novela de Guillermo Arriaga, Un dulce olor a muerte, a partir del análisis de las teorías de la traducción más relevantes en relación con el tratamiento de los elementos culturales (culturemas). En esencia, mediante el uso de las funciones del lenguaje definido por Nord (1994), respecto a las diferencias culturales en la traducción, nuestro objetivo es explorar las diversas prácticas culturales de transferencia, con el fin de centrarse en los aspectos lingüístico-culturales, dentro de la novela mexicana y su traducción, que ambos constituyen nuestro corpus. Por otra parte, tratamos de identificar los principales métodos de traducción que se han aplicado, con el propósito de establecer su porcentaje de uso y debatir sobre su funcionalidad.

Palabras clave: estudios de traducción, elementos culturales (culturemas), técnicas de traducción, idioma, cultura. 


\section{Abstract}

In this paper we propose to review, on a lexical and phraseological basis, the published translation into Romanian of Guillermo Arriaga's novel, A sweet scent of death, starting from analysing the most relevant translation theories in relation to the treatment of the cultural elements (culturemes). Essentially, by using the functions of language defined by Nord (1994), regarding the cultural differences in translation, we aim to explore several cultural transfer practices, in order to focus on the cultural-linguistic components, within the Mexican novel and its translation, which both constitute our corpus. Moreover, we attempt to identify the main translation methods that have been applied, with the purpose to establish their percentage of usage and to debate upon their functionality.

Keywords: translation studies, cultural elements (culturemes), translation techniques, language, culture

\section{Introducción}

Onocer las literaturas del mundo, aunque a través de las tra-
ducciones, significa descubrir al Otro, y ese mismo descubri-
miento está marcado por un profundo interés y curiosidad inte-
lectual y simboliza, según afirma el teórico Michel Ballard (1998:
11-24), el proceso que garantiza preservar la identidad cultural. El
presente artículo enfoca distintas teorías actuales en torno a la tra-
ducción de los elementos culturales específicos para una sociedad,
denominados culturemas, partiendo de las visiones funcionalistas
que tienen Nord y Agar sobre el papel del lenguaje, con respecto
a las diferencias expresivas que se dan entre un texto literario y su
respectiva traducción.
Nos proponemos analizar brevemente las teorías que aporta-
ron al tema de la traducción literaria en las últimas décadas, en- 
tre otros, Nida (1975), Reiss y Vermeer (1984), Oskaar (1988), Newmark (1988), Berman (1989), Nord (1994), Toury (1995), Hurtado Albir (2004), Molina Martínez (2006), con el fin de evidenciar sintéticamente sus criterios de tratamiento traductológico, su definición y su clasificación, aplicadas a las unidades mínimas portadoras de significado cultural. Tales estrategias y tipologías serán luego empleadas, de manera combinatoria, a nuestro corpus, representado por la novela Un dulce olor a muerte, de Guillermo Arriaga, y su versión traducida al rumano por nosotros, y publicada por primera vez en Rumania en el año 2008. Cabe mencionar que hemos considerado oportuno el presente estudio, ya que las cuestiones sometidas a la discusión y la distancia temporal, entre el detallado proceso de traducción y el mismo análisis, marcan pautas críticas para la funcionalidad del texto traducido.

Ante todo, señalamos que la presente investigación reúne dos niveles metodológicos descriptivo-comparativos, porque, por un lado, los ejemplos prácticos abordarán, desde el punto de vista léxico-fraseológico y semántico, algunas de las dificultades más substanciosas que intervinieron en el proceso de la transferencia cultural mexicano-rumana, haciendo hincapié en las técnicas de traducción utilizadas en calidad de traductor, a veces situadas al margen de la intraducibilidad; y respectivamente, por el otro lado, trataremos de indagar, en calidad de investigador sobre la traductología, acerca de las relaciones ideológicas que se dan entre las dos lenguas y culturas comparadas, con el propósito de debatir sobre la adecuación del tratamiento aplicado a los elementos culturales, además de su repercusión y su funcionalidad en el futuro. 


\section{En torno al corpus propuesto y sus retos literarios implícitos}

Traducir significa desplazar espiritualmente la obra de una cultura específica hasta otra cultura de acogida, fenómeno que supone una especie de traslado de elementos lingüísticos, culturales, sociales y antropológicos. Por lo general, toda literatura, junto a las demás manifestaciones artísticas y culturales, incluso las no verbales, plantean modelos de realidad propios para una determinada civilización y sociedad. En México, la novela ocupa un lugar peculiar en la cultura, desempeñando tanto un papel crítico, como otro representativo, que atańen a un crisol social muy diverso. Los referentes literarios de la novela $U n$ dulce olor a muerte apuntan hacia una atmósfera general que recuerda el aire de Crónica de una muerte anunciada, de García Márquez, mientras que los personajes pertenecen más a la Comala de Rulfo, entre sus apetencias de derrame de sangre y sueños furtivos causados por el bochorno, la muerte y otros dolores en vida, todo salpicado con toques categóricos de humor irónico. Más aun, la ambientación y las voces resultan familiares para los lectores de otra novela firmada por el mismo Arriaga, titulada Los tres entierros de Melquiades Estrada. En realidad, casi todos los vínculos intertextuales parecen indicar a otras obras conocidas que exploran ambientes rurales, cuyas dramas e historias demuestran ser universales, aunque pertenecen culturalmente a espacios distintos. Es verdad que la literatura traducida pasa luego a formar parte del acervo cultural propio de lengua de acogida. Por ello, creemos que cualquier traducción desencadena reacciones entre las dos lenguas y culturas que reflejan toda la problemática del proceso de adaptación, debido a una contextualización diferente, que supera la esfera puramente lingüística.

Concretamente, la traducción de las unidades lingüístico-culturales en la novela de Arriaga ha resultado ser un asunto complejo, 
que supuso un enfoque funcional y dinámico, e incluyó a menudo escollos en la comprensión total de los sintagmas, denominaciones específicas, frases hechas, modismos o palabrotas que salpicaban el texto original. Ya desde el principio, experimentamos retos significativos debido a la correspondencia escasa entre la cultura mexicana y la cultura rumana. Está claro que la lejanía cultural entre las dos civilizaciones se pone de manifiesto en la dificultad de encontrar equivalencias a cualquier elemento lingüístico castizo.

En primer lugar, apenas se puede hablar de una visión unitaria y correcta de una cultura por parte de la otra, a pesar del fondo latino antiguo, transmitido en épocas totalmente distintas, siglos XVI-XVI y siglos II-III, por el castellano, y, respectivamente por el latín vulgar. Asimismo, observamos que muchos signos culturales son inexistentes en la otra cultura, dado el entorno autóctono distinto: en la parte central de México se distingue el substrato cultural maya, zapoteca, otomí, mixteca, huasteca, azteca, entre muchos, mientras que, en el territorio rumano, más uniforme y reducido, contamos con escasas reminiscencias sedimentadas de la cultura tracia del norte, es decir geto-dacia, a la que se añade la latina, eslava, austro-húngara, turca.

Aunque nos referimos a un género literario que suele ser bastante flexible, el de la novela, cuyos elementos lingüístico-ficcionales pertenecen, desde el punto de vista de su naturaleza — metáforas, otras figuras de estilo, aspectos propios de la narración- al mismo ámbito; sin embargo, tanto en el texto original (TO), como en el texto meta de la traducción (TM), el registro sociocultural y las técnicas expresivas varían considerablemente. En este sentido, hay bastante diferencias incluso entre el castellano ibérico y el de México, lo que, a veces, entorpece el proceso de comprensión y búsqueda lingüística, puesto que el idioma rumano carece de cualquier variedad de "ultramar". 


\section{Traductología y el tratamiento de las unidades culturales}

La relación entre traducción y cultura ha sido debatida por muchos traductólogos, sobre todo después de la década de los años ochenta; los traductores bíblicos, Nida, Taber y Margot, siendo los primeros que ahondan en la conexión que se manifiesta entre los dos conceptos, e indagan sobre cuestiones ligadas a la transferencia cultural. De hecho, muchos estudiosos consideran la traducción como un fenómeno de comunicación intercultural, entre los cuales destacan Reiss y Vermeer (1984), Holz-Mänttäri (1984/1985), Oskaar (1988), Witte (1990).

Casi todos los planteamientos socioculturales que analizan la traducción desde un punto de vista contextual, ponen de relieve el papel de los elementos culturales dentro del proceso de la traducción. En este sentido, Basil Hatim e Ian Mason (1997) definen al traductor como mediador entre culturas, dedicando una función especial a la dimensión semiótica, mientras que la escuela de TelAviv (Itamar Even-Zohar y Gideon Toury), junto conde la escuela de la manipulación (coordinada por Theo Hermans) y todos aquellos que, en diversos lugares, siguen sus ejes programáticos (como José Lambert, en Lovaina) proponen inscribir cualquier traducción dentro un polisistema literario. Por ejemplo, G. Toury (1980/1995) plantea el análisis de la traducción como producto de la transferencia cultural, subrayando su protagonismo en la cultura meta e insiste especialmente en los datos empírico-descriptivos, como punto de partida para todo desarrollo teórico. El nuevo giro en la teoría de la traducción supone un consistente análisis del TM, con el propósito de examinar las relaciones de intertextualidad que mantiene con el TO y, a la vez, con otros textos de la cultura. Más adelante, se pasa del estudio interlingüístico, a otro, que incumbe 
la dimensión textual concreta, tal como se manifiesta en el producto mismo, que es una determinada traducción.

Sin embargo, nos preguntamos si semejante saber puramente descriptivo es, en sí mismo, suficiente al final, ya que evita la abstracción de las teorías clásicas, mas deja de lado el problema de la verdad de la traducción, es decir, la compleja relación que existe en torno a las obras literarias, expresada mayoritariamente a través del comentario y de la crítica, actividades esenciales para cualquier resultado práctico. Sin duda alguna, en el futuro habrá que desarrollar las correspondencias que se dan entre la traducción y otras reflexiones filosóficas, religiosas, psicoanalíticas, lo que acaso reivindicará cierto regreso a la normatividad, según sostiene Antoine Berman (1989).

Otro factor que hemos tenido en cuenta ha sido la relevancia de tales elementos culturales en el conjunto del texto, o sea, dentro del sistema lingüístico y semiótico, y si ésos desempeñan alguna función real. Tal como insisten Nord (1994) y Agar (1992), cada manifestación textual depende, además de su material lingüístico, de las convenciones y normas de cada cultura. En este caso, los autores citados indican cuatro funciones esenciales que expresan las diferencias culturales en la traducción.

Cuadro 1. Funciones del lenguaje y diferencias culturales en la traducción:

\begin{tabular}{|l|l|}
\hline \multicolumn{1}{|c|}{ FUNCIONES } & \multicolumn{1}{c|}{\begin{tabular}{c}
\multicolumn{1}{c|}{ DifERENCIAS ENTRE TO Y TM } \\
EN RELACIÓN CON LO SIGUIENTE:
\end{tabular}} \\
\hline Función fática & $\begin{array}{l}\text { Saludos, fórmulas de tratamiento, uso de } \\
\text { nombres propios } \\
\text { Silencios, pausas convencionales, muletillas } \\
\text { conversacionales }\end{array}$ \\
\hline
\end{tabular}




\begin{tabular}{|l|l|}
\hline Función referencial & $\begin{array}{l}\text { Acontecimientos, objetos, fenómenos, he- } \\
\text { chos, celebraciones sociales } \\
\text { Maneras de vivir, comer, vestirse }\end{array}$ \\
\hline Función expresiva & $\begin{array}{l}\text { Sentimientos, valores éticos y morales verba- } \\
\text { lizados }\end{array}$ \\
\hline Función apelativa & $\begin{array}{l}\text { Mecanismos de persuasión, retórica y tomas } \\
\text { de postura }\end{array}$ \\
\hline
\end{tabular}

Observamos que la primera y la última categoría aluden al carácter altamente funcional de la traducción y señalan lexemas, sintagmas y frases enteras que sirven para iniciar, mantener o acabar el acto de una comunicación, lo más específico del lenguaje conversacional, por lo tanto se circunscribirían básicamente a la esfera de la primera y segunda persona, singular y plural. La segunda y tercera categoría se refieren, de alguna manera, a la relación del individuo con el mundo, incluyendo a todas las personas en singular y plural, en función del discurso literario. Basta con afirmar que ese conjunto de valores, creencias y principios de vida suele ser compartido de modo diferente por cada grupo familiar, social, regional, etc.

En lo que nos concierne, aplicaremos semejante división funcional a nuestros trozos literarios seleccionados del corpus; sin embargo, recordamos que no todos los elementos que conforman la cultura son identificables, a nivel verbal o textual. Consecuentemente, al CuAdro i deberían añadirse las diferencias que atañen al comportamiento para-verbal: gestos y otros aspectos cinéticos, la distancia y las normas de protocolo entre interlocutores, el tono de voz o algunas restricciones mentales de conducta que rigen cada cultura. Todo ello podría debatirse en otra ocasión, un caso idóneo siendo la traducción de las obras de teatro.

Antes de proceder a las propuestas de clasificación de los elementos que configuran, a nivel del idioma, la cultura mexicana de la novela, plantearemos brevemente la finalidad de la traducción. 
Según Luciano Nanni (1991), cualquier elemento sociocultural determina y moldea otras tres voces obligatorias que actúan como filtros de comprensión, más exactamente, la del autor, la de la obra y la del lector. A primera vista, si aplicamos dichos filtros a la traducción de la novela de Arriaga, observaremos que tanto la cultura mexicana del autor, como la de la obra en sí, influyeron bastante sobre el TM, mientras que la cultura lingüística rumana de acogida ejerció un peso menor a nivel lingüístico, debido a la aclimatación (de)limitada del lector rumano a la atmósfera, de ahí el uso de una metodología distinta a la que deriva de la noción simplista de equivalencia o adaptación.

En los estudios de traductología, el término culturema ha adquirido significados parecidos entre sí y muchas aportaciones teóricas en los últimos cincuenta ańos, cada una, reflejo de las tendencias de investigación a lo largo de las épocas correspondientes. La relación entre lenguaje y cultura fue definida, a principios del siglo XIX, por Guillermo de Humboldt (1998: 27), considerando que el lenguaje cuando nombra, de hecho, crea y deja su marca en el pensamiento. Tal afirmación nos lleva a alegar que la lengua era considerada más una forma de pensamiento que un utensilio de comunicación, al encajar cada cultura dentro del universo semiótico de cierta comunidad, la que compartía los mismos idiomas y formas de pensar. Evidentemente, no hay una relación unívoca entre lengua y cultura, ya que dentro de la misma lengua se pueden dar comunidades diferentes, como es el caso del español y la mayoría de las culturas hispánicas. En cambio, lo que sí cabría examinar es si el alcance de la noción y su integración teórica-metodológica incumben más a los campos en torno a la lingüística y cuáles de ellos (lexicología, fraseología, pragmática) o, más bien, dominios como la antropología, la sociología, la morfología de la cultura o, simplemente, la traductología. Amparo Hurtado Albir recoge 
en su libro (2004: 614) diversas teorías y propuestas a ese último tema, de las cuales destacamos las consideraciones siguientes.

En la década de 1960, Catford aludía a la intraducibilidad cultural cuando el elemento de la TO no podía encontrar ninguna forma en la TM. En los años ochenta, se puso en circulación el término de giro cultural (cultural turn, Cfr. Bassnett y Lefevere), que indicaba la fuerte relación social entre los contextos culturales y la traducción, reivindicando la última como un proceso de comunicación intercultural. (Berenguer (1997), Reiss y Vermeer (1984), Witte (1987), Hewson-Martin (1991), Katan (1999) etc).

El origen de la definición del término culturema no resulta claro. Algunos autores lo atribuyen a Nord (1997: 34), otros a Oskaar (1988) y, en lo que nos atañe, coincidimos con otras opiniones, incluidas las de Nord, Mayoral Asensio o Hurtado Albir cuando afirman que se debe a Vermeer (1983: 8): "un fenómeno social de una cultura $A$, que es considerado relevante por los miembros de esta cultura, y que, cuando se compara con un fenómeno social correspondiente en la cultura B, se encuentra que es específico de la Cultura A. Otra estudiosa rumana insiste en una definición más práctica y detallada: el culturema sirve para designar un enunciado portador de información cultural o una unidad cultural de tamaño variable en el TO, y tiene que identificarse en el TM bajo forma y tamaño variable" (Georgiana Lungu Badea: 2001). Nosotros ańadiríamos que la noción indica la especificidad cultural de un país o región o simplemente de cierto ámbito cultural, siendo una unidad de comunicación, con estructura semántica y pragmática compleja y relevante para dicha comunidad y cuya traducción requiere un estudio y estrategia adecuados en cada caso. 


\section{Tipología de los culturemas}

Una de las cuestiones que se plantean a la hora de traducir es la creación de una tipología (en consecuencia, sería muy conveniente la creación de diccionarios consistentes de culturemas) que destaque los principales rasgos diferenciadores agrupados según sus temas y naturaleza. Los teóricos que recogemos a continuación (Nida, Vlakhov y Florin, Newmark, Katan, House, Ramadán, Molina Martínez) representan las aportaciones más destacadas a propósito del tratamiento de los culturemas.

Nida marca el inicio en el estudio y la identificación de los culturemas como problema clave de la traducción ([1945]1975) y en este sentido propuso cinco áreas distintas, retomadas por Margot (1979), las cuales serían las siguientes: diferencias de ecología; cultura matemática; cultura social; cultura religiosa y cultura lingüística. La iniciativa era meritoria entonces, aunque hay apartados coincidentes: por ejemplo, la cultura religiosa no tiene cabida si no forma parte de la cultura social, mientras que la cultura lingüística podría abarcar a todas ellas.

Vlakhov y Florin (1970) definieron el concepto de realia, refiriéndose a los elementos textuales que indican el color local, y señalaron cuatro tipos: geográficos y etnográficos; folclóricos y mitológicos; objetos cotidianos y elementos socio-históricos. Esta clasificación se centra demasiado en los elementos psico-antropológicos y de índole social-histórica, dejando al lado el sistema semiótico supuesto por la comunicación cultural. También faltan los valores éticos y morales ideológicos actuales. En cambio, otros autores, como Bödeker y Freese (1987) o Koller (1992) utilizan los términos realia, pero en sentido más amplio, aludiendo a realidades físicas o conceptuales peculiares de una cultura concreta.

De todas maneras, se abrieron espacios de debate que han culminado en la clasificación de Newmark (1988/1992: 133-146) en 
torno a las palabras culturales extranjeras —idéntica terminología que Nida-, que destaca las diferencias en los campos: ecología (flora y fauna); cultura material (objetos, productos, artefactos); cultura social (trabajo, ocio); organizaciones, costumbres, actividades, procedimientos y conceptos (políticos, administrativos, religiosos, artísticos); hábitos y gestos. Sobre todo, los dos últimos nos parecen una novedad notable, porque introducen tanto un dominio abstracto relacionado con la semiótica del pensamiento de cada cultura como un fundamento para-lingüístico, imprescindible para cualquier lengua.

Más adelante, House (1977) acuñó los términos overt y covert translation, —retomados por Ramadán (1991): traducción patente y encubierta-, para referirse a las traducciones en función de la distancia cultural existente entre éstas y sus textos de origen. En este marco se propone una categoría textual nueva, la "traducción patente — que, en las palabras de Ramadán — no disfruta de la misma condición del TO en el polisistema meta, por estar el TO específicamente ligado a las condiciones socio-culturales del polo de origen". Como consecuencia, formula House la necesidad de aplicar un "filtro cultural" para la traducción de las marcas culturales, y así se logre a superar las diferencias.

A su vez, Katan (1999: 45-47) clasificó las diferencias surgidas de la información cultural según los factores siguientes: el entorno; la conducta; las capacidades, estrategias y habilidades para comunicarse; los valores; las creencias y la identidad. Su propuesta resulta compleja, aunque hay niveles que no son del todo independientes, ni están totalmente definidos, de manera que la conducta no está motivada por las creencias de una cultura ni por sus valores, mientras que la identidad representaría la quintaesencia de todos y no una categoría aparte. Sin embargo, el autor señala con razón que los valores se distribuyen heterogéneamente dentro de la mis- 
ma comunidad, siendo compartidos de manera distinta por cada estrato social.

Más aun, Nida (1975) indica que la frecuencia de uso del vocabulario cultural dentro de cualquier comunidad es proporcional a la relevancia que tiene el ámbito correspondiente para dicha cultura; además, constan consecuencias y cambios lingüísticosemánticos sustanciales a raíz de fenómenos sociales tales como catástrofes, conquistas, guerras etc. Por lo tanto, en cada idioma se pueden distinguir léxicos "del lugar" altamente especializados, desde el punto de vista terminológico, que cada cultura ha desarrollado por necesidad y por defecto: el léxico del desierto en árabe, el léxico del frío y de la nieve en los países septentrionales, el léxico de la tauromaquia en español, etc.

Últimamente, destaca el estudio de Molina (2006) que, al analizar la novela Cien años de soledad, de García Márquez, y su traducción al árabe, construyó un sistema de diferencias culturales basado en los pilares del medio natural; el patrimonio cultural; la cultura social y la cultura lingüística.

Para concluir, la clasificación diseñada por Molina Martínez (2006: 78-79), enumera las siguientes características: a) los culturemas son contextuales y surgen en el seno de una transferencia cultural entre dos culturas A y B, y esa relación no se aplica a ninguna otra lengua o cultura $C$; $b$ ) la activación de los culturemas, simples o complejos, se refiere a la correspondencia real que se da entre ellos y alguna idea, algún objeto, hábito, actividad o emoción típica, con los que la sociedad descrita se identifica en un momento determinado, concediéndoles valor simbólico, a título de guía, referencia o modelo de (inter)acción-interpretación; $c$ ) las fuentes son innumerables y reflejan el aprendizaje de la sociedad correspondiente, desde textos religiosos, hasta chistes y refraneros, pero también en la literatura, el arte y los medios de comunicación; d) existen culturemas regionales, nacionales y urbanas, y otros supra- 
nacionales o universales que quizás se remonten al subconsciente colectivo defendido por Jung.

\section{Técnicas de traducción, entre teoría y práctica}

En lo que respecta a las técnicas de traducción, hay muchas discrepancias entre los teóricos antes mencionados, no sólo acerca de la terminología empleada, sino también en cuanto a su concepción. De momento, no existe una terminología unificada para denominar los tratamientos utilizados —en unos casos definidos como procedimientos, en otros como técnicas o estrategias-, mientras que entre las diversas clasificaciones formuladas se observan solapamientos de términos. Nuestro propósito metodológico no consiste en hacer una revisión crítica de todos los enfoques clasificatorios con sus pros y sus contras, sino tratar de plantear una visión funcional de las técnicas de traducción, en conformidad con el dinamismo de la equivalencia traductora. Al final, la técnica representa una opción del traductor que ha sido evaluada contextualmente y su validez está concedida por cuestiones diversas, como la finalidad de la traducción, las modalidades discutidas como posibilidades, las expectativas de los lectores, los cuales representan de hecho los verdaderos destinatarios, no los críticos ni los investigadores. En otras palabras, hay tonalidades distintas para cada acto traductor que cambian en función de lo siguiente: el tipo de texto y su papel desempeńado (por ejemplo, si tienen o no carácter divulgativo, si son obras infantiles y no pueden utilizarse notas); la importancia de cada elemento cultural en la cultura de origen y su grado de confianza y relevancia lingüística (novedad, referencialidad y uso futuro) en la cultura meta; las características del lector, su motivación y nivel cultural —bastante difícil de valorar, ya que la mayoría de las traducciones suelen dirigirse a un público general. 
Para nuestro corpus, las técnicas de traducción han significado esencialmente recurrir a unos procedimientos de clasificación y análisis del tratamiento empleado a los culturemas, que cumplirían las siguientes condiciones fundamentales: a) se refieren a microunidades textuales del corpus; $b$ ) son contextuales; $c$ ) son funcionales; d) reflejan una relación de trasvase, equivalencia o adecuación traductora entre TO-TM; $e$ ) su catalogación es espejo de una reflexión bilingüe y bicultural, es decir, siempre a raíz de una comparación.

A estas alturas, cabría preguntarse ¿por qué nos hemos planteado un análisis comparativo bilingüe? El argumento sería porque, gracias al trasvase cultural derivado de la traducción, se construye otro discurso más potente, el intercultural, y, de esta manera, uno puede investigar a fondo las lenguas y las culturas puestas en contacto. Antes de proceder a nuestra propuesta de clasificación, conviene recordar que las técnicas de traducción utilizadas por nosotros (e incluidas en el CUADRO 2) no representan unas categorías únicas e inamovibles para analizar el TM, ya que intervienen también elementos de coherencia, registro y cohesión estilística, otras dimensiones pragmáticas, retóricas e ideológicas, que podrían catalogarse en el futuro.

\section{Cuadro 2. Técnicas de traducción utilizadas \\ en la traducción del corpus:}

\begin{tabular}{|l|l|}
\hline \multicolumn{1}{|c|}{ TÉCNICA } & \multicolumn{1}{c|}{ DESCRIPCIÓN Y EJEMPLOS } \\
\hline Adaptación & $\begin{array}{l}\text { Reemplazar un elemento cultural del TO } \\
\text { por otro propio de la cultura del TM }\end{array}$ \\
\hline Ampliación lingüística & Ańadir elementos lingüísticos \\
\hline Amplificación & $\begin{array}{l}\text { Introducir precisiones no formuladas en } \\
\text { el TO } \\
\text { (las notas de pie de página) }\end{array}$ \\
\hline
\end{tabular}




\begin{tabular}{|l|l|}
\hline Calco & $\begin{array}{l}\text { Traducir literalmente una palabra o } \\
\text { sintagma extranjero }\end{array}$ \\
\hline Compresión lingüística & Sintetizar elementos lingüísticos \\
\hline Creación discursiva & $\begin{array}{l}\text { Establecer una equivalencia efímera, to- } \\
\text { talmente imprevisible fuera del contexto }\end{array}$ \\
\hline Descripción & $\begin{array}{l}\text { Reemplazar un término o una expre- } \\
\text { sión por la descripción de su forma o } \\
\text { función }\end{array}$ \\
\hline Equivalente acuñado & $\begin{array}{l}\text { Utilizar un término o expresión, recono- } \\
\text { cido a nivel lingüístico, como equivalen- } \\
\text { te en el TM }\end{array}$ \\
\hline Generalización & $\begin{array}{l}\text { Utilizar un término más general o } \\
\text { neutro }\end{array}$ \\
\hline Particularización & $\begin{array}{l}\text { Utilizar un término más preciso o } \\
\text { concreto }\end{array}$ \\
\hline Préstamo & $\begin{array}{l}\text { Integrar una palabra o expresión de otra } \\
\text { lengua tal cual } \\
\text { (puede ser puro, sin operar ningún } \\
\text { cambio, o normalizado a la grafía de la } \\
\text { lengua meta) }\end{array}$ \\
\hline Reducción & $\begin{array}{l}\text { Suprimir algún elemento informativo } \\
\text { del TO en el TM }\end{array}$ \\
\hline Transposición & Cambiar la categoría gramatical \\
\hline & \\
\hline
\end{tabular}

El interés de la novela para semejante análisis se asienta en la profusión de los elementos culturales sorprendidos por el ojo clínico cinematográfico del autor. La novela $U n$ dulce olor a muerte es una obra contextualizada a un lugar geográfico, es decir el mundo de Loma Grande, un pueblo del estado mexicano de Veracruz, cuya historia lo convierte en personaje central, atmósfera, voz colectiva que dirige la vida y muerte de los demás. En la terminología de House y Ramadán, citada anteriormente, estamos ante una traducción patente, es decir, un texto que resume algunas referencias culturales mexicanas concretas, separadas por una distancia física 
y estética de la cultura rumana. Por la autenticidad de la comparación, hemos preservado tanto el TO como el TM, exactamente bajo la forma de sus versiones impresas, eso sí, con los culturemas evidenciados en itálicas, pero sin otro cambio o traducción ulterior, que hubieran podido aclarar la restitución del sentido, pero no las técnicas utilizadas, que representan el aspecto clave de nuestro estudio.

5.1. Aquí hemos incluido ejemplos de elementos culturales con función referencial, según la teoría de Nord, y sus respectivos procedimientos de traducción, marcados tras cada ejemplo en negrita. Observamos que, por lo general, pertenecen al ámbito de flora y fauna, y es precisamente el hecho de que pertenezcan exclusivamente a la tierra considerada como polo de origen lo que determina su comportamiento como culturemas

\begin{tabular}{|l|l|l|l|}
\hline p. 9 & $\begin{array}{l}{[\ldots] \text { el gorjeo de }} \\
\text { tantas chachalacas }\end{array}$ & $\begin{array}{l}{[\ldots] \text { ciripitul atâtor }} \\
\text { chachalacas }\end{array}$ & p. 7 \\
\hline
\end{tabular}

PrÉSTAMO PURO + NOTA. Incluimos una nota descriptiva que detalla el ave galliforme de plumaje café verdoso y vientre blanco, voladora, de carne comestible. Había un término acuñado generalizador en rumano bibilică (gallina de Guinea), pero lo evitamos para resaltar el exotismo de la denominación.

\begin{tabular}{|l|l|l|l|} 
p. 39 & $\begin{array}{l}\text { Varios, conmovidos, les } \\
\text { regalaron puercos, galli- } \\
\text { nas y guajolotes. }\end{array}$ & $\begin{array}{l}\text { Mai mulți, impresionați, } \\
\text { le-au făcut cadou porci, } \\
\text { găini şi curcani. }\end{array}$ & p. 41 \\
\hline
\end{tabular}

EQUIVALENTE ACUŃADO: al tratarse del pavo en la versión mexicana, elegimos su correspondiente en rumano, sin matizar el americanismo. Lo mismo ocurre con la variación puerco/cerdo, cuyo significado es idéntico en los dos textos. 
p. 23 Carmelo se sacudió el

Carmelo şi-a scuturat brațul

p. 25 brazo izquierdo para quitarse de encima un stâng ca să-şi scoată un cosaş [...] chapulín [...]

Generalización: en realidad, es una especie de segador o cigarra, que en rumano recoge un término general conocido. A través de la generalización se pierde el potencial gastronómico del animal, muy popular en México, cuyos uso y denominación se remontan a la comunidad náhuatl. A estas alturas, destacamos que la versión sugerida en el diccionario rumano es lăcustă, que pertenece a la misma familia de los saltamontes, pero que es más grande y voraz, por lo cual no nos parece correcta su utilización.

\begin{tabular}{|l|l|l|l|}
\hline p. 36 & $\begin{array}{l}\text {-No estaban en su casa } \\
\text { —contestó—, los fui a } \\
\text { hallar cortando tunas en } \\
\text { el Bernal. }\end{array}$ & $\begin{array}{l}\text { —Nu erau acasă, —a } \\
\text { răspuns— abia i-am găsit, } \\
\text { tăind nopali la Bernal. }\end{array}$ & p. 38 \\
\hline
\end{tabular}

CAlCo + PARTICULARIZACión: de la familia de las cactáceas, denominada higuera de Indias, tiene higos cuya pulpa es comestible. El equivalente popular rumano limba-soacrei no refleja exactamente el mismo tipo de cacto, por lo tanto, consideramos más oportuno el calco.

\begin{tabular}{|l|l|l|l|}
\hline p. 15 & $\begin{array}{l}\text { Jacinto Cruz, matance- } \\
\text { ro de reses y enterrador } \\
\text { en el cementerio del } \\
\text { pueblo. }\end{array}$ & $\begin{array}{l}\text { Jacinto Cruz, măcelar la abator } \\
\text { şi groparul satului. }\end{array}$ & p. 15 \\
\hline
\end{tabular}

EQUIVALENTE ACUÑADO CON DESCRIPCIÓN + REDUCCIÓN. La profesión explica perfectamente el oficio desempeńado, por ello utili- 
zamos el equivalente acuñado măcelar (carnicero) al que añadimos el lugar del oficio abator (matadero). En el segundo caso, operamos una reducción del lugar (cementerio) para evitar la redundancia.

\begin{tabular}{|l|l|l|l|}
\hline p. 16 & $\begin{array}{l}\text { Le pusieron debajo un } \\
\text { petate }[\ldots]\end{array}$ & $\begin{array}{l}\text { I-au aşezat dedesubt un petate } \\
{[\ldots]}\end{array}$ & p.16 \\
\hline
\end{tabular}

PRÉSTAMO PURO + NOTA DESCRIPTIVA: etimológicamente proviene de la lengua azteca, donde se denominaba petatl cualquier estera, muy utilizada en los países tropicales.

\begin{tabular}{|l|l|l|l|}
\hline p. 32 & $\begin{array}{l}\text { —iY si le inyectamos } \\
\text { chinguere? }\end{array}$ & 一Şi dacă îi injectăm chinguere? & p. 34 \\
\hline
\end{tabular}

PrÉSTAMO PURO + GENERALIZACIÓn. La nota se refiere a cualquier aguardiente de baja calidad o muy común.

\begin{tabular}{|l|l|l|l|}
\hline p. 18 & $\begin{array}{l}\text { La viuda Castańos des- } \\
\text { escamaba unas tilapias } \\
\text { que le habían regalado }\end{array}$ & $\begin{array}{l}\text { Văduva Castańos curăța de } \\
\text { solzi nişte tilapias pe care îi } \\
\text { primise cadou [...] }\end{array}$ & p. 18 \\
\hline
\end{tabular}

DESCRIPCIÓN + PRÉSTAMO / ADAPTACIÓN. Una curiosidad del rumano es la inexistencia de un verbo como desescamar, por lo tanto lo parafraseamos con quitar las escamas, técnica que sugiere la descripción de la costumbre de cocina. A continuación, al no haberse encontrado un equivalente adecuado para dicho pescado, se ha utilizado el préstamo combinado con la generalización incluida en una nota (pez muy voraz, de la familia de los Cicladas) o, en otros contextos posteriores, la adaptación cultural que alude a un pescado parecido denominado caras de mare. 
5.2. Esta categoría reúne los ejemplos cuya función es tanto referencial como expresiva, y que han requerido unas técnicas más elaboradas o combinadas en el proceso de traducción.

\begin{tabular}{|l|l|l|l|}
\hline p. 39 & $\begin{array}{l}{[\ldots] \text { mandó llamar - }} \\
\text { en cambio-a los dos } \\
\text { evangelistas que radica- } \\
\text { ban en el ejido Pastores. }\end{array}$ & $\begin{array}{l}\text { [... şi —în schimb-a a } \\
\text { trimis să-i cheme pe cei doi } \\
\text { evanghelişti care se stabiliseră }\end{array}$ & p. 37 \\
& in comuna Pastores. & \\
\hline
\end{tabular}

AdaptaCión. El establecimiento denominado ejido varía por cada estado y región. En México se conoce como ejido a las propiedades rurales de uso colectivo que todavía existen. En Rumanía, semejante agrupación territorial (C.A.P) ya no existe desde la época de la dictadura comunista, por lo tanto optamos por un léxico neutro que indica casi una traslación cultural. Como significado, la palabra rumana refleja varios pueblos y propiedades rurales que comparten la misma división administrativa.

\begin{tabular}{|l|l|l|l|}
\hline p. 19 & $\begin{array}{l}\text { Todos deseaban estar } \\
\text { [...], olisquear el cadá- } \\
\text { ver, hurgar en la pena } \\
\text { ajena. }\end{array}$ & $\begin{array}{l}\text { Toți doreau[...], să se afle aco- } \\
\text { lo, zgândăreau cuțitul în rana } \\
\text { altuia. }\end{array}$ & p.19 \\
\end{tabular}

Equivalente acuñado. Como técnica, desde el punto de vista funcional, este procedimiento resulta mucho más dinámico que, por ejemplo, una traducción literal. En este caso, la variante rumana propone una expresión similar, con la misma tonalidad estilística.

\begin{tabular}{|l|l|l|l|}
\hline p. 74 & $\begin{array}{l}\text {-Ándale pues - } \\
\text { dijo- me voy a callar, } \\
\text { sólo quiero hacer una } \\
\text { última pregunta. }\end{array}$ & $\begin{array}{l}\text { - Păi bine, atunci —zise—o } \\
\text { să, vreau numai să pun o } \\
\text { ultimă întrebare. }\end{array}$ & p. 76 \\
\hline
\end{tabular}


Creación discursiva + AMPlificación. Ándale como órale son locuciones verbales típicas, y, como curiosidad, señalamos el uso de le neutro que abunda en el habla familiar. El significado es contextual, a veces apelativo, y anima a la acción, mientras que otras veces es una exhortación o, simplemente, la afirmación de algo: ¡eso es! , ¡claro! en nuestro caso.

\begin{tabular}{|l|l|l|l|}
\hline p. 19 & $\begin{array}{l}\text { —Quiubo paisanos, } \\
\text { ¿por qué tanto alboro- } \\
\text { to? }\end{array}$ & $\begin{array}{l}\text {-Ce s-a intâmplat, fraților, de } \\
\text { ce atâta gălăgie? }\end{array}$ & p. 23 \\
\hline
\end{tabular}

Creación discursiva + AMPliación lingüística. Esa interjección expresa un popular y extendido saludo familiar o amistoso de bienvenida afectuosa, pero al tratarse de la policía rural y de una trama de homicidio, hemos preferido la fórmula qué pasa, hermanos en rumano, lo que indica una creación contextual discursiva.

\begin{tabular}{|c|c|c|c|}
\hline p. 22 & $\begin{array}{l}\text { —QQué pasó animal de } \\
\text { uña? } \\
\text { —Aquí nomás, animal } \\
\text { de pezuña. }\end{array}$ & $\begin{array}{l}\text {-Care-i treaba, animal cu } \\
\text { gheare? } \\
\text { —Păi, ce să fie, animal cu } \\
\text { copite. }\end{array}$ & p. 24 \\
\hline
\end{tabular}

Creación Discursiva de expresiones fáticas, respetando el mismo juego de palabras.

\begin{tabular}{|l|l|l|l|}
\hline p. 74 & $\begin{array}{l}\text { Un ratón pasó corrien- } \\
\text { do por encima de la } \\
\text { mesa, cogió un pedazo } \\
\text { de tortilla abandonado } \\
{[\ldots]}\end{array}$ & $\begin{array}{l}\text { Un şoarece trecu în fugă pe } \\
\text { masă, luă o bucată de tortilla }\end{array}$ & p. 77 \\
\hline lăsată $[\ldots]$ & & \\
\hline
\end{tabular}


Préstamo puro + Amplificación. El falso amigo refleja una de las situaciones donde se impone como sugerencia de mejora, proporcionar alguna nota explicativa, porque las diferencias gastronómicas entre el castellano peninsular y el de ultramar pueden causar confusiones. Parece que los aztecas preparaban ya antes de la conquista espańola varios tipos de tortillas; sin embargo el autor se refiere a la más difundida por México, que es la tortilla de maíz o trigo, con harina y agua, significado totalmente diferente con respecto a la tortilla española, a lo mejor más conocida para el lector rumano, dado el mismo marco gastronómico europeo.

\begin{tabular}{|l|l|l|l|}
\hline p. 69 & $\begin{array}{l}\text { Su madre, al verla tan } \\
\text { mortificada, quiso } \\
\text { aliviarle la desazón } \\
\text { plantándole compresas } \\
\text { de toloache sobre las } \\
\text { sienes. }\end{array}$ & $\begin{array}{l}\text { Maică-sa, când a văzut-o atât } \\
\text { de îngrozită, a vrut să-i aline } \\
\text { neliniştea punându-i comprese } \\
\text { cu toloache pe la tâmple. }\end{array}$ & p. 71 \\
& & \\
\hline
\end{tabular}

PrÉstamo PURO + AMPLIFICACión. La nota detalla que la planta pertenece al mismo género que el estramonio, y que es una de las plantas medicinales muy utilizadas por los aztecas, debido a sus propiedades psico-activas, analgésicas y alucinógenas. Ulteriormente, encontramos una planta de la misma familia en rumano ciumăfaia (Datura stramonium), que podría haber funcionado felizmente en el TM en lugar de toloache (Datura ferox), sin la resonancia local, pero con más acierto lingüístico.

5.3. La presente clase abarca las licencias literarias, los coloquialismos, palabrotas y vulgarismos que contienen elementos erróneos en el castellano estándar desde el punto de vista gramatical. La complejidad de la traducción reside en la dificultad de encontrar un equivalente expresivo o apelativo en rumano, que suele regirse por normas lingüísticas distintas (cortesía, usos verbales socialmen- 
te aceptados). Sin embargo, la solución propuesta no debe tampoco deformar excesivamente el TM, aunque no refleje los mismos errores gramaticales o licencias literarias, se pueden preservar los fines irónicos y sarcásticos.

\begin{tabular}{|l|l|l|l|}
\hline p. & -Ahhh Justino, si serás & -Ah! Justino, chiar că eşti un & p. 24 \\
23 & cabrón. & ticălos.
\end{tabular}

CREACión Discursiva + ADAPTACión. La propuesta de traducción trata de revelar el mero sentido comunicativo que desgraciadamente no hunde tanto los personajes en su incultura.

\begin{tabular}{|l|l|l|l|}
\hline p. 23 & $\begin{array}{l}\text { — ¿Se murió o la murie- } \\
\text { ron? }\end{array}$ & -A murit sau au omorât-o? & p. 25 \\
\hline
\end{tabular}

ADAPTACión. El rumano no permite semejante transitivización del verbo, por consiguiente optamos, por el verbo «a omorî» cuyo significado es matar.

\begin{tabular}{|l|l|l|l|}
\hline p. 22 & $\begin{array}{l}\text {-Pos nada compita, que } \\
\text { me amanecí con hartas } \\
\text { ganas de saludarte. }\end{array}$ & $\begin{array}{l}\text {-Păi, mai nimica, colega, } \\
\text { m-am trezit c-un chef nebun } \\
\text { să te salut. }\end{array}$ & p. 24 \\
\hline
\end{tabular}

Creación discursiva + adaptación. Pos reemplaza el pues en su calidad de cobran difícilmente el mismo color local en rumano, por consiguiente, respetamos el estilo medio familiar, medio irónico, haciendo uso de palabras funcionales.

\begin{tabular}{|l|l|l|l|}
\hline p. 60 & $\begin{array}{l}{[\ldots] \text { su madre nunca se }} \\
\text { matrimonió. }\end{array}$ & $\begin{array}{l}{[\ldots] \text { maică-sa care niciodată }} \\
\text { nu şi-a pus pirostriile pe cap. }\end{array}$ & p. 62 \\
\hline
\end{tabular}


AdAPTACión + AMPLIACIÓN LINGüÍsTICA. La inexistencia de un verbo reflexivo para matrimoniar y el contexto de uso sugieren un tono más burlón e irónico que el habitual, motivo por el cual respetamos el mismo registro en rumano.

p. $53-[\ldots]$ ahora nos vamos $-[\ldots]$ acum. Ne vom ocupa cu p. 55 a dedicar al bisnes de la „bisnisul« pescuitului. pescada.

Calco. Señalamos el intento de rumanización de una palabra inglesa que en el TO revela su pertenencia a un spanglish deformado, con el propósito de obtener el mismo efecto irónico.

5.4. Entre el fervor pasional y los sabores extremos de la jerga mexicana, hemos ilustrado aquí los ejemplos más interesantes para la traducción de la novela de Arriaga, cuya función, sobre todo expresiva, nos ha costado más ingenio y trabajo lingüístico.

p. 23 -La murieron... y a la malagueña: le zamparon un cuchillo en la mera espalda. p. 25

un mod tâlhăresc: i-au vârât

cuțitul chiar pe la spate.

Creación discursiva + Descripción. El significado se explica justo después de la frase, que corresponde a una expresión jergal nacional. Como la traducción literal no resultaba nada expresiva, nuestra variante sostiene más el discurso y la traducción comunicativa. 


\begin{tabular}{|c|c|c|c|}
\hline p. 54 & $\begin{array}{l}\text {-Pinche sorgo - in- } \\
\text { tervino Torcuato- } \\
\text { de haber sabido que lo } \\
\text { pagaban a trescientos } \\
\text { ciencuenta, ni para qué } \\
\text { lo siembro. }\end{array}$ & $\begin{array}{l}\text { — La naiba cu sorgul —a } \\
\text { intervenit Torcuato— să } \\
\text { fi ştiut că îl plătesc cu trei } \\
\text { sute cincizeci, nici nu mă } \\
\text { oboseam să semăn. }\end{array}$ & $\begin{array}{l}\text { p. } \\
56\end{array}$ \\
\hline p. 24 & $\begin{array}{l}\text { - Pinche gente compa } \\
\text { - prosiguió Lozano-, } \\
\text { no se civiliza, todavía se } \\
\text { matan por pendejadas. }\end{array}$ & $\begin{array}{l}\text {-Oameni de nimic, frate- - } \\
\text { a adăugat Lozano—, nu se } \\
\text { civilizează, încă se mai ucid } \\
\text { pentru tâmpenii. }\end{array}$ & $\begin{array}{l}\text { p. } \\
26\end{array}$ \\
\hline
\end{tabular}

Creación discursiva + AdAPtación. Al tratarse de voces malsonantes, otra vez recurrimos a una traducción funcional, que explica el significado y se aleja de la forma, indicando casi una traslación cultural. Pinche persona en español designa una persona que presta servicios auxiliares en la cocina, pero como adjetivo mexicano significa despreciable, pendejo y equivale al mentecato en el DRAE, o sea, muy torpe.

\begin{tabular}{|l|l|l|l|}
\hline p. 25 & $\begin{array}{l}\text {-Fíjate que no se } \\
\text { puede. } \\
\begin{array}{l}\text {-No friegues —repuso } \\
\text { Carmelo. }\end{array}\end{array}$ & $\begin{array}{l}\text {-Uite că nu se poate. } \\
\text {-Nu mă nerva - a replicat } \\
\text { Carmelo. }\end{array}$ & p. \\
\hline p. 25 & $\begin{array}{l}\text {-Compita ¿para qué } \\
\text { fregados te metes en } \\
\text { asuntos que no te in- } \\
\text { cumben? }\end{array}$ & $\begin{array}{l}\text {-Colega, de ce Dumnezeu îți } \\
\text { bagi nasul acolo unde nu-ți } \\
\text { fierbe oala? }\end{array}$ & p. 28 \\
\hline
\end{tabular}

Creación discursiva + ADAPTACión. El rumano no acepta igual que el castellano las invectivas en la lengua hablada, por ello, nuestra elección es más suave que el registro empleado por el TO. Por lo general, fregada indica una mala y difícil situación, aunque su significado resulta polisemántica, ello sirve para moldear el fastidio 
y enfado del locutor, muy parecido a la chingada, que representa el colmo de la grosería.

\begin{tabular}{|l|l|l|l|}
\hline p. 25 & $\begin{array}{l}\text {-No chingues, Carme- } \\
\text { lo, mejor deja las cosas } \\
\text { como están. }\end{array}$ & $\begin{array}{l}\text {-Nu glumi, Carmelo, mai } \\
\text { bine lasă lucrurile aşa cum } \\
\text { sunt. }\end{array}$ & p. 27 \\
\hline p. 52 & $\begin{array}{l}\text {-Ya ni la chingan }[\ldots] \\
\text { con esos precios no vale } \\
\text { la pena cosechar. }\end{array}$ & $\begin{array}{l}\text { - ISsi bat joc }[\ldots] \text { la prețurile } \\
\text { astea un merită să recoltezi. }\end{array}$ & p. 54 \\
\hline p. 73 & $\begin{array}{l}\text { [...] mata a ese hijo de } \\
\text { la chingada... }\end{array}$ & $\begin{array}{l}\text { [...] omoară-l pe ticălosul ăsta } \\
\text { dat naibii... }\end{array}$ & p. 75 \\
\hline
\end{tabular}

CREACión DISCURSIVA + ADAPTACión

\begin{tabular}{|l|l|l|l|}
\hline p. 56 & $-[\ldots]$ ese cabrón del & $-[\ldots]$ ticălosul ăla de Țigan & p. 58 \\
& $\begin{array}{ll}\text { Gitano se la pasaba } \text { chu- } \\
\text { leándome mi cuchillo... }\end{array}$ & $\begin{array}{l}\text { incerca tot timpul să-mi } \\
\text { șterpelească cuțitul. (opción } \\
\text { incorrecta) } \\
\text {-[...] ticălosul ăla de Țigan } \\
\text { tot timpul imi lăuda cuțitul. } \\
\text { (opción correcta) }\end{array}$ & \\
\hline
\end{tabular}

TÉrmino aCuñado (SUgerencia de MEJORA) + REDUCCión. A primera vista, un lector peninsular entendería el verbo como un sinónimo coloquial de robar (hurtar, birlar), lo que ha sido nuestra primera opción también, pero que es, en definitiva, un falso amigo. Para los mexicanos, chulear significa elogiar, solución encontrada mucho después y que, desgraciadamente, carece de equivalente coloquial en rumano, por lo que recurrimos a la reducción del registro y no del significado. 


\begin{tabular}{|l|l|l|l|}
\hline p. 53 & $\begin{array}{l}-[\ldots], \text { como que des- } \\
\text { de hace tres días quiere } \\
\text { soplar un vientecito } \\
\text { huasteco. }\end{array}$ & $\begin{array}{l}\text { vrea să bată un vânticel huastec. } \\
\text { vă }\end{array}$ & p. 56 \\
\hline
\end{tabular}

PRÉSTAMO + NOTA para uno de los sintagmas más difíciles por concebir semánticamente; en la nota especificamos que los huastecos representan un pueblo indígena precolombino de México, conquistados por los aztecas, los cuales habitan principalmente los estados San Luis Potosí, Hidalgo, Veracruz y Tamaulipas. La indicación del autor se refiere a un punto cardinal del noroeste y oeste, pero queda poco definido, por no haber encontrado todas las referencias en los mapas actuales.

\begin{tabular}{|l|l|l|l|}
\hline p. 63 & $\begin{array}{l}\text { Hurgó dentro de una } \\
\text { caja, sacó una lata de } \\
\text { atún, otra de chicharros, } \\
\text { un frasco de mayonesa, } \\
\text { uno de chile chipotle } \\
\text { y una bolsa de pan } \\
\text { Bimbo. }\end{array}$ & $\begin{array}{l}\text { A cotrobăit într-o cutie, a } \\
\text { scos o conservă de ton, alta } \\
\text { de merlucius, un borcan } \\
\text { de maioneză, unul de chili } \\
\text { chipotle şi o pungă cu pâine }\end{array}$ & p. 65 \\
Bimbo. & \\
\hline
\end{tabular}

PARTICULARIZACIÓN + PRÉSTAMO PURO + NOTA AMPLIFICADORA. La entera descripción de ingredientes y el imaginado deleite del paladar convierten el acto de la traducción en una experiencia casi gastronómica, tan apreciada por el espíritu mexicano auténtico. En realidad, el órgano del gusto no es la lengua, sino el cerebro, un órgano determinado culturalmente, a través del cual se aprenden y transmiten los criterios de aceptación y reconocimiento, acepción coincidente con la de Newmark, cuando sostiene que la comida es la expresión más delicada e importante de la cultura nacional. En cambio, aquí nos topamos irónicamente con una descripción absurda de comida chatarra, global, mezclada con elementos del 
lugar que ingieren los personajes de una comunidad en medio de la nada. Chicharro podría denominar el chicharrón (residuos de las pellas de cerdo) o, en femenino, otro tipo de chapulines; sin embargo, en el caso señalado hace referencia a un tipo de pescado, indiferenciado en el diccionario. Consecuentemente, elegimos en rumano un término acuñado merlucius de que es de lo más parecido al original, en cuanto al aspecto. Con chile chipotle añadimos una nota para el calco, y la variación de origen náhuatl, chipotle, que indica el tipo de ahumado; mientras que para el pan Bimbo optamos por el préstamo acompañado por una nota amplificadora que indica el pan de molde de una marca comercial determinada.

$\mathrm{Al}$ reflexionar sobre los elementos culturales analizados en los apartados anteriores, aunque el corpus examinado representa solamente la mitad de la novela mexicana, observamos que las técnicas de traducción han sido muy diversas, destacando las siguientes: la adaptación (neutra, funcional, cultural), la ampliación lingüística, la creación discursiva, el préstamo puro acompańado por notas, el equivalente acuñado, la descripción, la generalización y la particularización. En lo que a los porcentajes de uso respecta, sumados al carácter específico de la novela, se condiciona un equilibrio entre el préstamo puro y la amplificación con notas, por una parte, y la creación discursiva o la adaptación funcional, por otra, tal como se puede observar a continuación. 
Cuadro 3. Técnicas de traducción utilizadas en la traducción al rumano de la novela Un dulce sabor a muerte, de Guillermo Arriaga

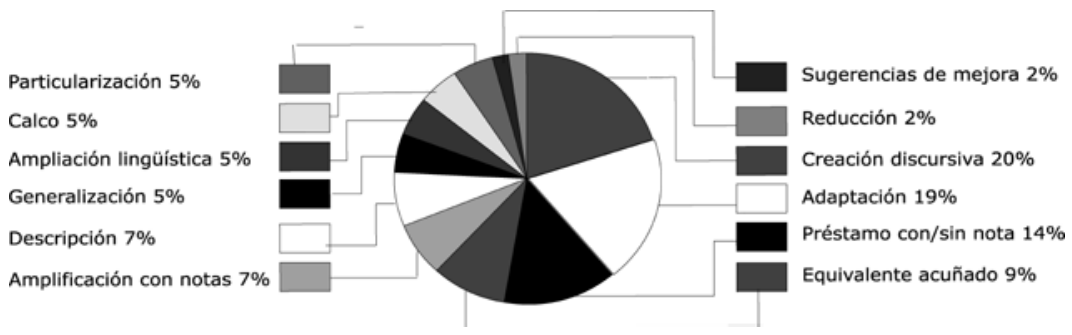

En concreto, la técnica de los préstamos, utilizada sobre todo en las primeras unidades que designan flora, fauna, hábitos sociales, referentes culturales, logra transmitir el exotismo propio de la novela y su color local, mientras que, mediante las adaptaciones y las creaciones discursivas, presentes mayoritariamente en la última categoría que incluye jerga mexicana, modismos, licencias literarias, el lector del TM puede sentir a flor de piel en rumano cómo piensan y actúan los habitantes del mundo dibujado por Arriaga.

\section{Reflexiones finales}

Seguramente, dentro de unos años, dicha traducción requerirá unas adaptaciones, según como la sociedad de acogida del TM vaya introduciendo nuevos hábitos culturales y vocablos en su lenguaje contemporáneo. Cierto es que no se puede reducir una obra de cualquier género a las características que le impongan la tradición del país en el que nace. Consideramos que la calidad de una novela es independiente de cualquier circunstancia física y que, además, solamente el autor y el traductor pueden comunicar su propia visión de la realidad. Es por eso que la narrativa de Arriaga en $U n$ dulce olor a muerte destaca por la configuración acertada de los 
paisajes y su entorno, impregnados por una serie de sentimientos que son entendibles a nivel universal, a pesar de las diferencias del idioma. Respecto a las traducciones literarias en general, no hay recetas generales de éxito, pero si entre las dos culturas no se dan muchos contactos en presente, como es el caso entre la mexicana y la rumana, resulta aconsejable adoptar una vía media, la de la traducción comunicativa-funcional, con escasos elementos exotizantes. $Y$ ¿quién sabe? si con el tiempo y en un mundo global, todo lo exótico pasará a ser compartido entre las culturas, con lo cual perderá la cualidad de culturema y se convertirá en fondo significante, enteramente armónico, sin necesidad alguna de recurrir a técnicas extremas.

A modo de conclusión, la traducción de los culturemas en la novela de Arriaga ha supuesto tres ámbitos distintos de reflexión. Uno de ellos se ha referido a la contextualización del TO y del $\mathrm{TM}$, lo que incumbe, respectivamente, su localización geográfica y social, el marco de otras influencias de obras, la intertextualidad y sus traducciones previas, si proceden. Un segundo pilar ha sido el intento de establecer una estructura o tipología, empleada para culturemas más relevantes encontrados en el corpus, con el fin de calibrarlos, al compás del esquema propuesto por Nord. Por ende, el tercer pilar, más consistente, ha significado, realizar a nivel teórico-descriptivo, un inventario de las técnicas de traducción utilizadas y su frecuencia de uso, que podrían aplicarse luego en tratamientos a elementos culturales similares.

El objetivo último de la presente investigación quisiera plantearse fomentar el análisis del funcionamiento del trasvase de los culturemas en la traducción. Aquí pensamos en que se podría ampliar el análisis de las técnicas de traducción desde la aproximación descriptiva hacia una apreciación valorativa, hasta tipologías más sólidas y unitarias al respecto. Además, sería interesante aumentar el volumen del corpus analizado para poder llegar a resultados más 
fidedignos o también dedicar este tipo de análisis a otros géneros textuales.

\section{Bibliografía}

Ballard, M., 1998, "La traduction comme conscience linguistique et culturelle: quelques repères", en Michel Ballard (ed.), Arras, Artois Presses Université / Ottawa, Presses de l'Université d'Ottawa, pp. 11-24.

Berenguer, L., 1997, L'ensenyament de llengües estrangeres per a traductors. Didàctica de l'alemany (tesis doctoral), Universidad Autónoma de Barcelona, Barcelona.

Berman, A., 1989, "La traduction et ses discours", Centre Jacques Amyot, París, Francia. Meta, XXXIV, 4. Consultada en http://www.erudit.org/revue/meta/1989/v34/n4/002062ar.pdf. La traducción de J. J. Gómez Montoya es una revisión de la versión publicada en Colección Hermes, Cuadernos Pedagógicos, núm. 3, Medellín, noviembre de 2005. Consultada en http://aprendeenlinea.udea.edu.co/revistas/ index.php/mutatismutandis/article/viewFile/10718/9938

Hatim, B. e I. Mason, 1997, The Translator as Communicator, Londres.

Humboldt, Guillermo de, 1998, Über die Verschiedenheit des menschlichen Sprachbaues und ibren Einfluß auf die geistige Entwicklung des Menschengeschlechts, Paderborn.

Hurtado Albir, A., 2004, Traducción y traductología. Introducción a la traductologia, Cátedra, Madrid.

Katan, D., 1999, Translating Cultures. An Introduction for Translators, Interpreters and Mediators, St. Jerome, Manchester.

Lungu-Badea, G., 2001, "Culturemele între conotații şi aluzii culturale. încercare de definire a conceptului de culturem", en Analele Universității de Vest din Timişoara, Seria Ştiințe Filologice, AUT, XXXIX, Timişoara, pp. 369-383. 
— , 2004, Teoria culturemelor, teoria traducerii, Universitatății de Vest, Timişoara.

Luque Nadal, L., 2009, "Los culturemas, ¿unidades linguísticas, ideológicas o culturales?”. Consultado en: elies.rediris.es/Language_Design/LD11/LD11-05-Lucia.pdf.

Molina Martínez, L., 2006, El otoño del pingüino. Análisis descriptivo de la traducción de los culturemas, Castellón de la Plana, Universidad Jaime I, Castellón. Consultado en: http://books.google.ro/books?id=GUl1Ls$36 \mathrm{CgC} \&$ printsec $=$ frontcover $\& \mathrm{dq}=\mathrm{El}+$ oto $\% \mathrm{C} 3 \% \mathrm{~B} 1 \mathrm{o}+\mathrm{del}+$ ping $\%$ $\mathrm{C} 3 \% \mathrm{BCino},+$ Molina + Martinez\&hl $=$ ro\&sa $=\mathrm{X} \& \mathrm{ei}=\mathrm{xncVT} 9 \mathrm{HPN}$ 4 arsgbmoLXCBQ\&ved=0CC4Q6AEwAA\#v=onepage \&q=El\%20 oto $\%$ C3\%B 1 o\%20del\%20ping\%C3\%BCino\%2C\%20Molina\%20Martinez\&f=false

Nanni, Luciano, 1991, Tesi di Estetica (a Umberto Eco in forma di risposta), Book Editore, Bologna.

Newmark, P., 1988, A textbook of Translation, Prentice Hall, Londres.

_ 1998 , More paragraphs on translation, Multilingual matters, Clevedon.

Nida, E. A., 1975, "Linguistic and ethnology in translation problems", en Exploring Semantic Structures, Wilhelm Fink Verlag, Múnich, pp. 194-208.

Nord, Ch., 1994, "It's tea-time in Wonderland. Cultura-makers in fictional texts", en Intercultural Communication, Leang, Duisburg.

—_, 1997, Translating as a Purposeful Activity: Functionalist Approaches Explained, St. Jerome Publishing, Manchester.

Oskaar, E., 1988, Kulturemtheorie. Ein Beitrag zur Sprachverwendungsforschung, Vandenhoeck \& Ruprecht, Göttingen.

Presas, M., 1999, "Un enfoque modular de la didáctica: Tareas para la adquisición de la competencia traductora”, en Pilar Elena et. al., (eds.), Universo de Palabras. Actas del I Simposio de la Traducción dell 
al Alemán, Facultad de Traducción y Documentación, Salamanca, pp. 381-393.

Ramadán, R, 1991, Equivalencia y traducción, Universidad de León, León.

Reiss K. y H. Vermeer, 1984, Grundlegung einer allgemeinen Translationstheorie, Niemeyer, Tubinga.

Rodríguez Abella, R. M., 2008, "La traducción de los culturemas en el ámbito de la gastronomía" en Revista internazionale di tecnica della traduzione, núm. 10. Consultado en: http://www.openstarts.units.it/ dspace/handle/10077/3376

Rodríguez Monroy, A., 1999, El saber del traductor, Montesinos-Ensayo, Barcelona. Consultado en: http://books.google.ro/books?id=eLaf51 vtzLAC\&pg=PA172\&lpg=PA172\&dq=escuela + de + Tel + Aviv + trad uccion \&source $=$ bl\&ots $=1 \mathrm{PPGwx} 82 \mathrm{y} 4 \&$ sig $=\mathrm{zSExaz} 0 \mathrm{Lb} 6 \mathrm{tgq} 7 \mathrm{VIhT}$ nqfVPvX78\&hl=ro\&sa=X\&ei=dQoPT67rJo7U4QTAu8DZAw\& ved=0CGoQ6AEwCQ\#v=twopage $\&$ q=escuela $\% 20 \mathrm{de} \% 20 \mathrm{Tel} \% 20$ Aviv\%20traduccion\&f=true

Toury, G., 1995, Descriptive Translation Studies and Beyond, John Benjamins, Amsterdam.

Vermeer, H. J., 1983, “Translation theory and linguistics”, en Näkökhtia käänämisen tutkimuksesta, P. Roinila, R. Orfanos y S. TirkkonenCondit (eds.), Joensuu, Univ. of Joensuu, pp. 1-10.

Vlakhov, S. y S. Florin, 1970, “Neperevodimoe v perevode: realii”, en Masterstvo perevoda, Sovetskii pisatel, Moscú, pp. 432-456.

\section{Diccionarios}

Diccionario de la Real Academia Espańola, 1994, 21 a ed., Espasa Calpe, Madrid.

Calciu, A., C. Duhăneau y D. Munteanu, 1979, Dicționar român-spaniol, Ştiințifică şi Enciclopedia, Bucarest. 
Calciu, A. y Z. Samharadze, 1992, Dicționar spaniol- român, Ed. Ştiințifică, Bucarest.

http://www.academia.org.mx/pdfs/DiccMexicanismos.pdf

http://www.scribd.com/doc/18649748/Diccionario-de-Mexicanismos

http://www.hispanosnet.com/diccionarios_online/diccionarios_vocablos_expresiones/vocablos_mexicanos/index.html

http://www.taringa.net/posts/info/961892/Diccionario-de-terminosmexicanos.html

http://dexonline.ro/

\section{Corpus}

Arriaga, G., 1999, Un dulce olor a muerte, Espasa Narrativa, Madrid.

_, 2008 , Un dulce miros de moarte, Olivia Petrescu (trad. y notas), Ed. Vellant, Bucarest. 